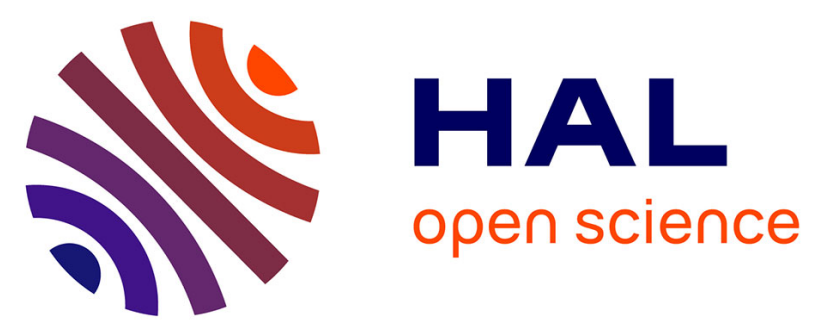

\title{
Origin of $\operatorname{Pr} 3+$ luminescence in hafnium silicate films: combined atom probe tomography and TEM investigations
}

Rémi DEMOUlin, Georges Beainy, Celia Castro, Philippe Pareige, Larysa Khomenkova, Christophe Labbé, Fabrice Gourbilleau, Etienne Talbot

\section{To cite this version:}

Rémi DEMOULIN, Georges Beainy, Celia Castro, Philippe Pareige, Larysa Khomenkova, et al.. Origin of Pr 3+ luminescence in hafnium silicate films: combined atom probe tomography and TEM investigations. Nano Futures, 2018, 2 (3), pp.2. 10.1088/2399-1984/aad009 . hal-01845624

\section{HAL Id: hal-01845624 https://hal.science/hal-01845624}

Submitted on 26 Aug 2018

HAL is a multi-disciplinary open access archive for the deposit and dissemination of scientific research documents, whether they are published or not. The documents may come from teaching and research institutions in France or abroad, or from public or private research centers.
L'archive ouverte pluridisciplinaire HAL, est destinée au dépôt et à la diffusion de documents scientifiques de niveau recherche, publiés ou non, émanant des établissements d'enseignement et de recherche français ou étrangers, des laboratoires publics ou privés. 


\title{
Origin of $\mathrm{Pr}^{3+}$ luminescence in hafnium silicate films: combined atom probe tomography and TEM investigations
}

\author{
Rémi Demoulin $^{1}$, Georges Beainy ${ }^{1}$, Célia Castro ${ }^{1}$, Philippe Pareige $^{1}$, Larysa Khomenkova ${ }^{2,3}$ (1), \\ Christophe Labbé ${ }^{2}$, Fabrice Gourbilleau ${ }^{2}$ and Etienne Talbot ${ }^{1}$ ic \\ 1 Normandie Univ, UNIROUEN, INSA Rouen, CNRS, Groupe de Physique des Matériaux, 76000 Rouen, France \\ Normandie Univ, ENSICAEN, UNICAEN, CEA, CNRS, CIMAP, 14000 Caen, France \\ Present address: V. Lashkaryov Institute of Semiconductor Physics at the National Academy of Sciences of Ukraine, 45 Prospekt Naury, \\ Kyiv 03028, Ukraine. \\ E-mail: etienne.talbot@univ-rouen.fr
}

Keywords: hafnium silicates, rare-earth ions, atom probe tomography, photoluminescence, phase transformation

\begin{abstract}
Structural, chemical, and luminescence properties of $\mathrm{Pr}^{3+}$-doped $\mathrm{HfSiO}_{x}$ layers fabricated by radiofrequency magnetron sputtering were examined as a function of annealing temperature. Phase separation between $\mathrm{SiO}_{2}$ and $\mathrm{HfO}_{2}$ as well as the location of $\mathrm{Pr}^{3+}$ dopants were investigated using atom probe tomography and transmission electron microscopy while optical properties of $\mathrm{Pr}^{3+}$ ions were studied using photoluminescence measurements. As a result, (i) we evidenced the location of the $\mathrm{Pr}^{3+}$ dopants in the $\mathrm{HfO}_{2}$ phase while the $\mathrm{SiO}_{2}$ phase was discovered to be free of these dopants, (ii) the $\mathrm{HfO}_{2}$ phase was identified to crystallize in the cubic phase until $1050{ }^{\circ} \mathrm{C}$ annealing, (iii) no Pr clusters were detected as function of annealing, and (iv) luminescence properties were discussed in regard to the location of $\mathrm{Pr}$ in the $\mathrm{HfO}_{2}$ cubic phase.
\end{abstract}

\section{Introduction}

Hafnium silicates $\left(\mathrm{HfSiO}_{x}\right.$ ) are considered as one of the most promising highly dielectric materials to replace $\mathrm{SiO}_{2}$ in complementary metal-oxide semiconductor technology [1]. This can be ascribed to their good thermal and chemical stabilities on Si wafer, their wide optical bandgap (5.7 eV), and their high refractive index [1-3]. Moreover, due to their lower phonon frequencies compared to $\mathrm{SiO}_{2}$, these $\mathrm{HfSiO}_{x}$ matrices are expected to be suitable hosts for efficient activation of rare-earth (RE) optical emission. Finally, because of the large bandgap of $\mathrm{HfSiO}_{x}$, which makes it transparent in the UV to IR range, this material is a promising host matrix for optical applications. RE ions are frequently used for light-emitting devices due to the variety of electronic levels allowing us to tune optical emission in the UV to IR range [4,5]. Nevertheless, only a few studies have been performed on RE-doped $\mathrm{HfSiO}_{x}$, with particular attention on $\mathrm{Er}^{3+}$-doped films [6-11]. The structural properties of these materials at the nanoscale level were investigated by transmission electron microscopy (TEM) [7, 9], which enabled us to reveal a phase separation between an amorphous $\mathrm{SiO}_{2}$ and a tetragonal $\mathrm{HfO}_{2}$ phase caused by high annealing temperature. Pure $\mathrm{HfO}_{2}$ can exist in four crystalline phases, as presented in figure 1, depending on the conditions (temperature, pressure, etc). The most stable phase formed at normal conditions (ambient pressure and temperature lower than $\left.1700{ }^{\circ} \mathrm{C}\right)$ is the monoclinic one (m- $\mathrm{HfO}_{2} \mathrm{P} 2_{1} / c$, figure $1(\mathrm{a})$ ), whereas the tetragonal (t- $\mathrm{HfO}_{2} \mathrm{P}_{2} / n m c$, figure 1(b)) and cubic (c- $\mathrm{HfO}_{2} \mathrm{~F} m \overline{3} m$, figure 1(c)) phases of pure $\mathrm{HfO}_{2}$ appear at high temperatures $[12,13]$. However, the orthorhombic phase (o- $\mathrm{HfO}_{2} \mathrm{Pca}_{1}$, figure $1(\mathrm{~d})$ ) has also been observed at room temperature in $\mathrm{Si}, \mathrm{Al}$, and $\mathrm{Gd}$-doped $\mathrm{HfO}_{2}$ [14]. As can be seen from figure 1, similarity exists between the different phases. Moreover, metastable tetragonal or cubic phases can also be stabilized at room temperature by doping the $\mathrm{HfO}_{2}$ matrix with $\mathrm{RE}$ atoms, as recently demonstrated for Ce-doped $\mathrm{HfO}_{2}$ nanoparticles [10] and Ladoped $\mathrm{HfO}_{2}$ films [11]. The tetragonal $\mathrm{HfO}_{2}$ phase was also confirmed by XRD in the $\mathrm{Er}^{3+}$-doped $\mathrm{SiO}_{2}-\mathrm{HfO}_{2}$ waveguide [8]. It was proposed that the introduction of $\mathrm{RE}^{3+}$ ions both in $\mathrm{HfO}_{2}$ and $\mathrm{HfSiO}_{x}$ changes the coordination number of $\mathrm{Hf}^{4+}$ cations, which can be substituted by $\mathrm{RE}^{3+}$ ions in the lattice with a formation of vacancies in the oxygen sublattice $[10,15,16]$. 


\section{a) monoclinic}

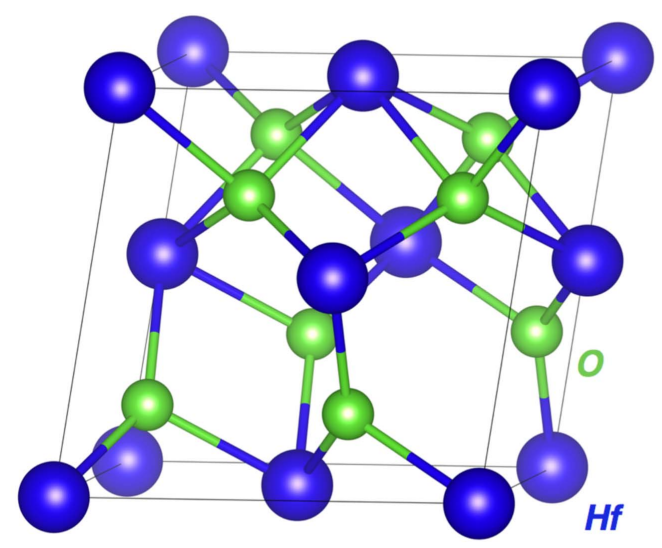

$P 2 / c$

$a=5.12 \AA, b=5.18 \AA, c=5.29 \AA, \beta=99.2^{\circ}$

\section{c) cubic}

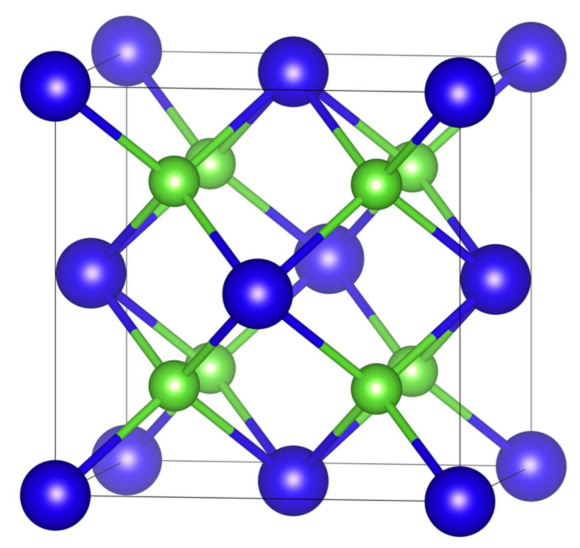

$F m \overline{3} m$

$a=5.09 \AA$ b) tetragonal

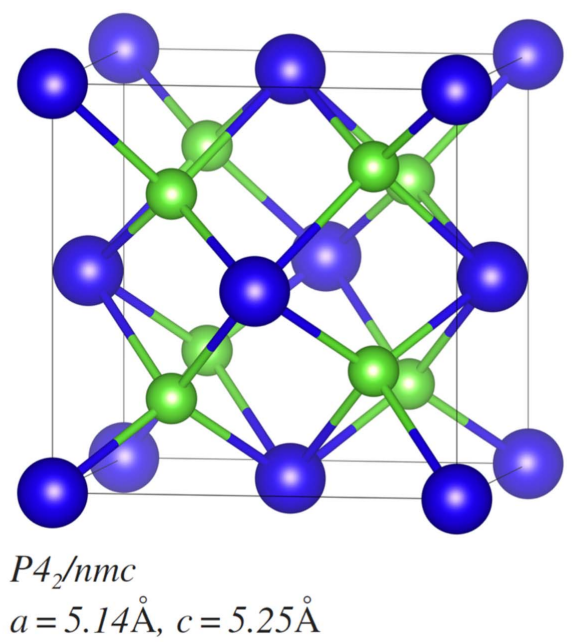

d) orthorhombic

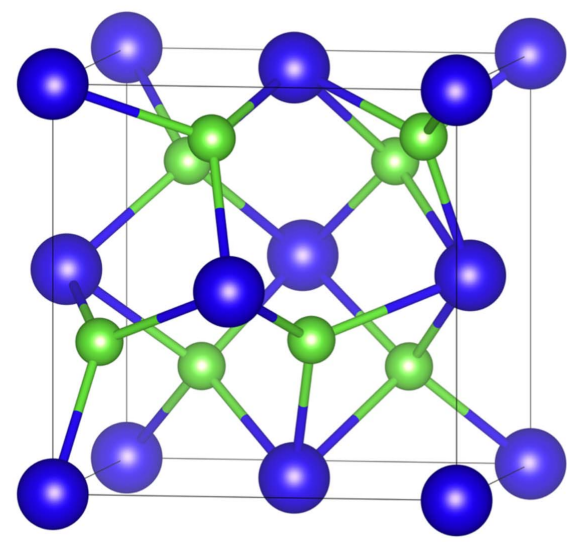

Pca2 1

$a=5.04 \AA, b=5.23 \AA, c=5.06 \AA$

Figure 1. Polymorph structures of (a) monoclinic, (b) tetragonal, (c) cubic, and (d) orthorhombic $\mathrm{HfO}_{2}$ phases. Hf atoms (big) are blue, and $\mathrm{O}$ atoms (small) are green.

Recently, the luminescence of $\mathrm{Pr}^{3+}$ ions in the visible spectral range was observed in the $\mathrm{Pr}$-doped $\mathrm{HfSiO}_{x}$ layer produced by magnetron sputtering [17]. A maximum of luminescence intensity was obtained for a $1000^{\circ} \mathrm{C}$ annealing, and the signal was attributed to an efficient excitation by oxygen vacancies located in the $\mathrm{HfO}_{2}$ phase. The structural properties were investigated by FTIR, XRD, and TEM, showing the phase separation between the $\mathrm{HfO}_{2}$ and $\mathrm{SiO}_{2}$ phases after such a high annealing temperature as well as the crystalline nature of the $\mathrm{HfO}_{2}$ phase similar to that in $\mathrm{Er}^{3+}$-doped $\mathrm{HfSiO}_{x}$ films [6-9]. However, the knowledge of an accurate atomic structure of the hosting material, particularly the local environment of $\mathrm{Pr}^{3+}$ ions, can be important to improve and optimize $\mathrm{Pr}-$ based photonic devices. In this paper, we investigate the effects at the atomic scale of annealing temperature on the structure of $\mathrm{Pr}$-doped $\mathrm{HfSiO}_{x}$ thin films produced by magnetron sputtering, using atom probe tomography (APT) and TEM.

\section{Experimental section}

\subsection{Sample preparation}

$\mathrm{Pr}^{3+}$-doped $\mathrm{HfSiO}_{x}$ was deposited on top of (100) $250 \mu$ m thick 2" Si wafers by radio-frequency magnetron cosputtering of a pure $4^{\prime \prime} \mathrm{HfO}_{2}$ target (99.9\% Testbourn Ltd.) topped by calibrated $1 \mathrm{~cm}^{2} \mathrm{Si}$ and $\mathrm{Pr}_{6} \mathrm{O}_{11}$ chips. Prior to the deposition run, the deposition chamber was maintained at a vacuum of $10^{-7}$ torr; during the run, the plasma pressure was fixed at $1.5 \mathrm{mTorr}$. Note that due to the geometry of the chamber, the substrate holder was not rotating. Before deposition, the substrates were subjected to standard RCA cleaning, dipped in a diluted 10\% 


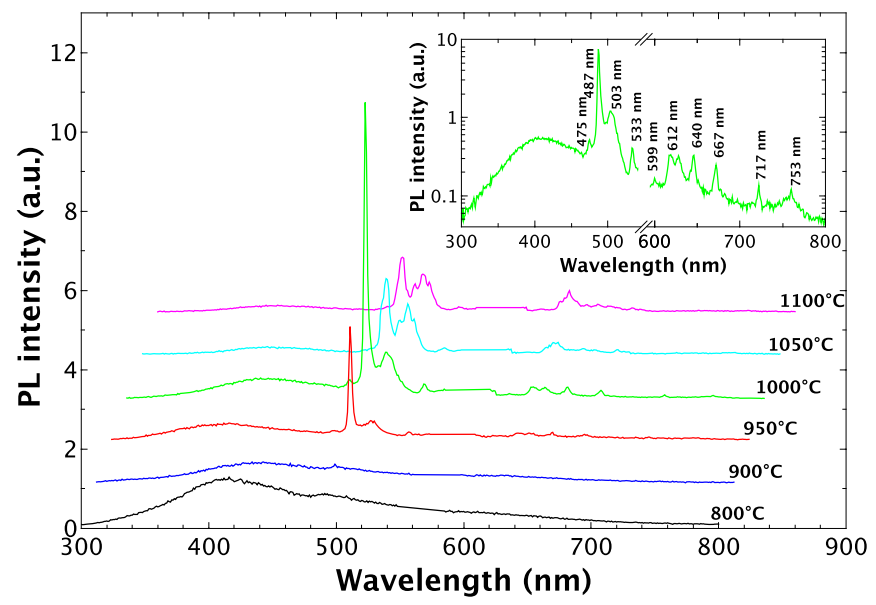

Figure 2. PL spectra of the $\mathrm{Pr}$-doped $\mathrm{HfSiO}_{x}$ films annealed at different temperatures $\left(\mathrm{T}_{A}=800{ }^{\circ} \mathrm{C}\right.$ to $\left.1100{ }^{\circ} \mathrm{C}\right)$. The excitation wavelength is $285 \mathrm{~nm}$. Inset shows the PL spectrum in logarithmic scale for the films annealed at $\mathrm{T}_{A}=1000{ }^{\circ} \mathrm{C}$.

HF solution, dried in $\mathrm{N}_{2}$, and then transferred to the deposition chamber. The films were fabricated with a radiofrequency power density of $0.98 \mathrm{~W} \mathrm{~cm}^{-2}$ in a pure Ar plasma, and a substrate temperature of $25^{\circ} \mathrm{C}$. The optimized deposition conditions were determined on the basis of previous works done on similar Er-doped systems $[6,18]$. Finally, an annealing treatment was performed under a $\mathrm{N}_{2}$ flow at temperatures varying from $800{ }^{\circ} \mathrm{C}$ up to $1050{ }^{\circ} \mathrm{C}$ for $1 \mathrm{~h}$.

\subsection{Structural and chemical characterization}

Chemical and structural analyses of the samples annealed at $800^{\circ} \mathrm{C}, 950{ }^{\circ} \mathrm{C}$, and $1050{ }^{\circ} \mathrm{C}$ were achieved by APT using a laser-assisted wide-angle tomographic atom probe (LAWATAP-Cameca). APT is a three-dimensional (3D) high-resolution analytic microscopy that allows the spatial mapping of atoms in a sample. The APT process is based on the field evaporation of surface atoms from the tip-shaped sample with a curvature radius lower than $50 \mathrm{~nm}$. Tips were prepared using a dual beam Zeiss NVision 40 FIB-SEM, by employing the lift-out and annular milling method [19]. APT experiments were conducted by applying UV femtosecond laser pulses $(\lambda=343 \mathrm{~nm})$ with a pulse energy of $20 \mathrm{~nJ}$, in an analysis chamber under a vacuum of $10^{-10} \mathrm{mbar}$. The APT data were reconstructed and analyzed using the Groupe de Physique des Matériaux's data treatment code. Cross-section TEM samples were prepared by mechanical polishing and Ar ion milling procedures. High-resolution TEM (HRTEM), selected area electron diffraction (SAED), scanning TEM (STEM), high angle annular dark field (HAADF), and electron energy loss spectroscopy (EELS) were performed on a field emission probe Cs aberration-corrected JEOL-ARM200F operating at $200 \mathrm{kV}$. EELS was performed on a GIF Quantum (Gatan) in a DUAL-EELS mode allowing us to simultaneously acquire the zero loss peak and the chosen signal. In this way any energy shift occurring during the acquisition could be corrected.

\subsection{Photoluminescence (PL) measurements}

PL experiments were carried out using a Jobin Yvon fluorolog spectrometer. The excitation source was a $450 \mathrm{~W}$ xenon arc lamp, and all spectra recorded at room temperature were corrected of the spectral response of the system.

\section{Results and discussion}

\subsection{PL properties}

The PL spectra in the UV to NIR spectral range registered for Pr-doped $\mathrm{HfSiO}_{x}$ films as a function of annealing temperature are shown in figure 2. A more detailed investigation of PL and PL excitation spectra has already been performed and can be found in [17]. PL signals of $\mathrm{Pr}^{3+}$ ions were observed only after annealing at $\mathrm{T}_{A} \geqslant$ $950{ }^{\circ} \mathrm{C}$ as sharp PL peaks associated with characteristic intra- $4 f$ transitions of $\mathrm{Pr}^{3+}$ ions (see the inset of figure 2 ). For $\mathrm{T}_{A} \geqslant 950^{\circ} \mathrm{C}$, the spectra show a strong luminescence intensity at $487 \mathrm{~nm}$ corresponding to the characteristic ${ }^{3} \mathrm{P}_{0} \rightarrow{ }^{3} \mathrm{H}_{4}$ transition of $\mathrm{Pr}^{3+}$ ions. The highest $\mathrm{Pr}^{3+}$ luminescence was detected for $\mathrm{T}_{A}=1000{ }^{\circ} \mathrm{C}$. The increase in intensity with the annealing temperature rising from $800{ }^{\circ} \mathrm{C}$ to $1000^{\circ} \mathrm{C}$ can be attributed to the decrease in the nonradiative recombination rates during the annealing process. At higher temperatures $\left(T_{A}\right.$ $>1000^{\circ} \mathrm{C}$ ), in addition to the intensity decrease, it is interesting to observe some slight modifications in the PL 


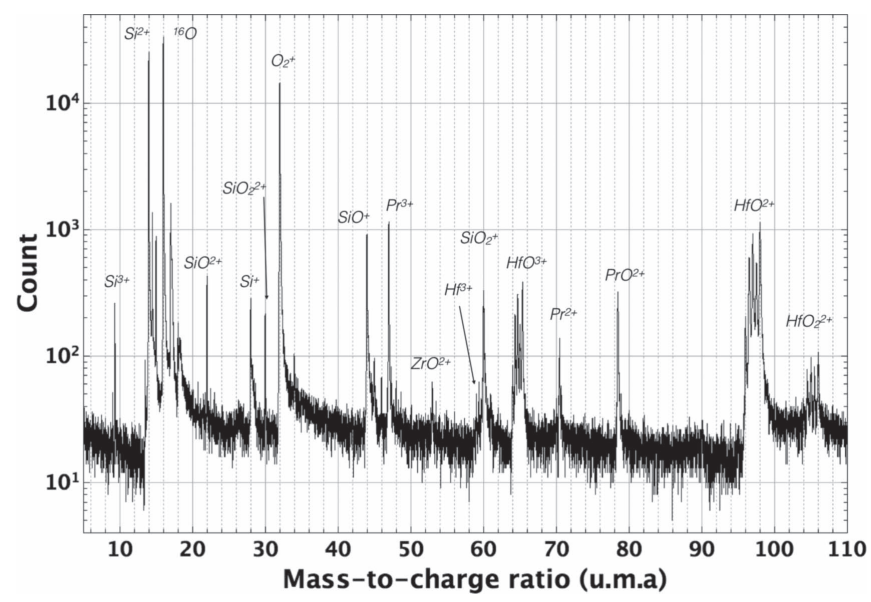

Figure 3. Mass spectrum collected by APT experiment on Pr-doped $\mathrm{HfSiO}_{x}$ film annealed at $1050{ }^{\circ} \mathrm{C}$.

Table 1. Atomic concentration of Si, O, Hf, and Pr atoms depending on the nature of the ${ }^{16}$ O peak.

\begin{tabular}{lcccc}
\hline $\mathrm{HfSiO}_{x}: \operatorname{Pr} @ 1050{ }^{\circ} \mathrm{C}$ & $\mathrm{Si}($ at.\%) & $\mathrm{O}($ at.\%) & $\mathrm{Hf}($ at.\%) & Pr(at.\%) \\
\hline if $^{16} \mathrm{O}=\mathrm{O}_{2}^{2+}$ & $14.1 \pm 0.3$ & $70.6 \pm 0.4$ & $12.0 \pm 0.3$ & $3.3 \pm 0.1$ \\
if $^{16} \mathrm{O}=\mathrm{O}^{+}$ & $16.3 \pm 0.3$ & $66.1 \pm 0.4$ & $13.8 \pm 0.3$ & $3.8 \pm 0.2$ \\
\hline
\end{tabular}

spectra. In fact, the position of the principal peak of emission redshifts from $487 \mathrm{~nm}$ at $\mathrm{T}_{A}=1000{ }^{\circ} \mathrm{C}$ to $492 \mathrm{~nm}$ at $\mathrm{T}_{A}=1100{ }^{\circ} \mathrm{C}$. Moreover, the peak associated with the ${ }^{3} P_{0} \rightarrow{ }^{3} \mathrm{H}_{4}$ transition at $503 \mathrm{~nm}$ splits into three different peaks, and the two peaks issued from the ${ }^{1} D_{2} \rightarrow{ }^{3} H_{4}$ transition at 612 and $623 \mathrm{~nm}$ become one peak centered at $617 \mathrm{~nm}$ at $1050{ }^{\circ} \mathrm{C}$. All of these changes in PL spectra can be caused by the structural evolution of the matrix during the annealing process and principally by a significant evolution of the environment of $\mathrm{Pr}^{3+}$ ions. In fact, the formation of Pr clusters as it was observed for other RE elements in a silica matrix [20,21], or the crystallization of the $\mathrm{HfO}_{2}$ phase in the matrix involving the modification of the crystal field near $\mathrm{Pr}^{3+}$ ions at high temperature, can affect the optical properties of the materials. To understand the origin of the modifications observed in the PL spectra, a thorough study of the microstructure is required.

\subsection{APT results}

The atom probe mass spectrum obtained for the Pr-doped $\mathrm{HfSiO}_{x}$ sample annealed at $1050{ }^{\circ} \mathrm{C}$ is shown in figure 3 . All the mass peaks are well identified in term of species and charged states except the peak at 16 amu $\left({ }^{16} \mathrm{O}\right)$. In fact, the real origin of this peak in metal-oxide matrices is still unclear; it could be identified as the evaporation of $\mathrm{O}^{+}$or $\mathrm{O}_{2}^{2+}$ ions, or a mix of both. For instance, in $\mathrm{SiO}_{2}$ matrices it was shown that $\mathrm{O}$ atoms were mainly evaporated in the form of $\mathrm{O}_{2}^{2+}$ [22], whereas in $\mathrm{Fe}_{2} \mathrm{O}_{3}$ metallic oxide these atoms were identified as $\mathrm{O}^{+}$ [23]. As a consequence, the real origin of this ${ }^{16} \mathrm{O}$ peak seems to be strongly dependent on the nature of the metal-oxide matrix. Therefore, in the case of a bi-phased system, here composed of $\mathrm{SiO}_{2}$ and $\mathrm{HfO}_{2}$, the ${ }^{16} \mathrm{O}$ peak origin can be different depending on the phase. One case of the $\mathrm{HfSiO}_{x}$ matrix has already been studied by an atom probe [24]. It was shown that the use of the $\mathrm{O}_{2}^{2+}$ form could give the compositions of the $\mathrm{SiO}_{2}$ and $\mathrm{HfO}_{2}$ phases that are expected in these kinds of systems. The precise nature of this peak will be discussed after $\mathrm{HfO}_{2}$ phase identification by TEM. Concerning the other species, $\mathrm{Si}$ is detected $\mathrm{Ss}^{+} \mathrm{i}^{+} \mathrm{Si}^{2+}$, and $\mathrm{Si}^{3+}$, and as molecular ions $\mathrm{SiO}^{+}, \mathrm{SiO}_{2}^{+}, \mathrm{SiO}^{2+}$, and $\mathrm{SiO}_{2}^{2+}$. Besides, we can see that $\mathrm{Hf}$ elements are mainly detected as molecular ions $\mathrm{HfO}^{2+}, \mathrm{HfO}^{3+}$, and $\mathrm{HfO}_{2}^{2+}$. Finally, Pr ions are identified as $\mathrm{Pr}^{2+}, \mathrm{Pr}^{3+}$, and $\mathrm{PrO}^{2+}$. Moreover, we detected a peak at $53.5 \mathrm{amu}$, which can be attributed to the molecular ions $\mathrm{ZrO}^{2+}$. This observation, also detected in STEM-EDS analysis (not shown here), can be explained by the presence of $\mathrm{Zr}$ traces in the $\mathrm{HfO}_{2}$ target, and appeared in all analyzed samples. No Ga ions were detected, indicating that there was no Ga implantation during the FIB milling process of the tip preparation, which could damage the microstructure. The mean chemical composition of samples was computed from mass spectra by considering the two possibilities for the ${ }^{16} \mathrm{O}$ peak, and is reported in table 1 .

As we can see, the chemical nature of this peak does not significantly impact the composition of the sample. This can be explained by the large number of $\mathrm{O}$ atoms that are evaporated in the form of molecular ions during the experiment (figure 3). Finally, considering previous studies made on $\mathrm{HfSiO}_{x}$ by APT [24, 25], further 
a)

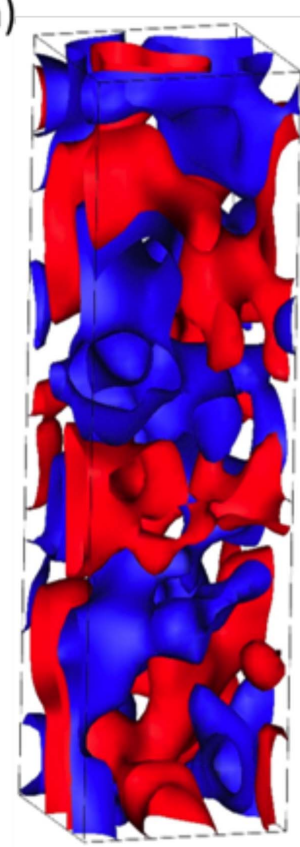

b)

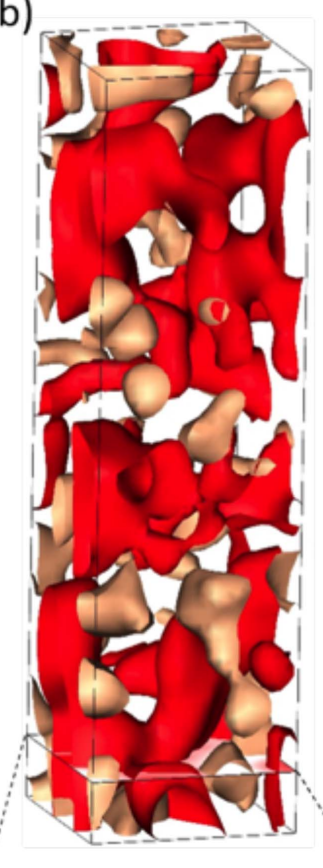

c)

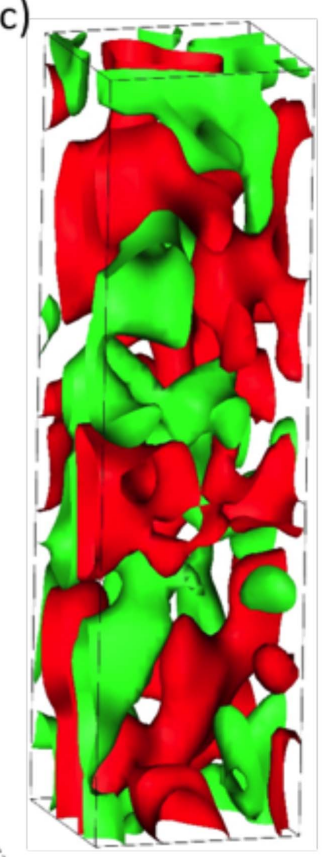

d)

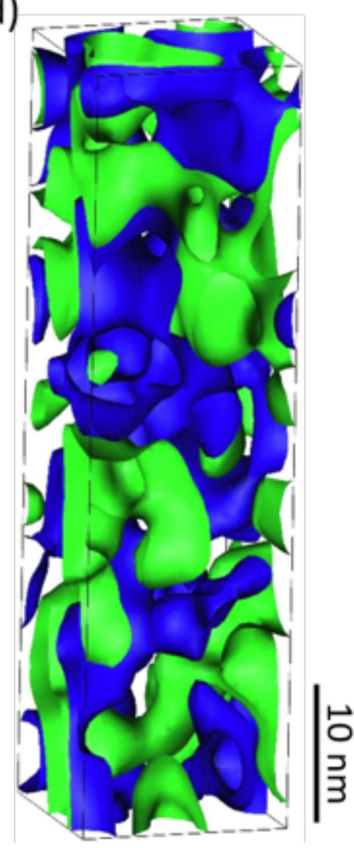

e)

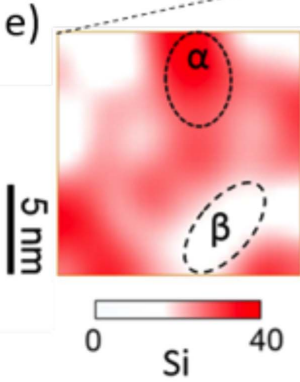

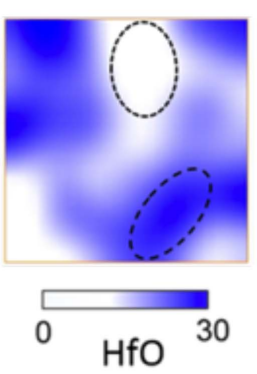
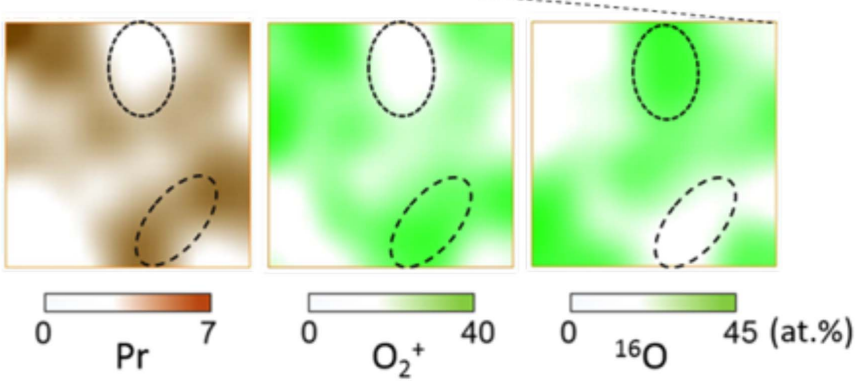

Figure 4. 3D isoconcentration surfaces for $\mathrm{Pr}$-doped $\mathrm{HfSiO}_{x}$ film annealed at $1050{ }^{\circ} \mathrm{C} .3 \mathrm{D}$ isosurfaces of (a) $\mathrm{Si}$ (red) and $\mathrm{HfO}$ (blue), (b) $\mathrm{Si}$ (red) and $\mathrm{Pr}$ (brown), (c) $\mathrm{Si}$ and $\mathrm{O}_{2}^{+}$(green), and (d) $\mathrm{HfO}$ and ${ }^{16} \mathrm{O}$ (green) concentrations are represented in a volume of $15 \times 15 \times 55 \mathrm{~nm}^{3}$. Thresholds are $\mathrm{X}_{\mathrm{Si}}=30$ at. $\%, \mathrm{X}_{\mathrm{HfO}}=20$ at. $\%, \mathrm{X}_{16 \mathrm{O}}=33$ at. $\%, \mathrm{X}_{\mathrm{O}_{2}^{+}}=27$ at. $\%$, and $\mathrm{X}_{\mathrm{Pr}}=2$ at. $\%$. (e) Isoconcentration slices extracted from the selected region, for each map the volume is $15 \times 15 \times 0.65 \mathrm{~nm}^{3}, \alpha$ and $\beta$ represent Si-rich and Hf-rich phases, respectively.

calculations will take into account this ${ }^{16} \mathrm{O}$ peak as $\mathrm{O}_{2}^{2+}$. No difference in the overall concentration has been observed as a function of the annealing temperature.

As predicted by the pseudo-binary phase diagram, and as it has been previously evidenced, a phase separation between $\mathrm{SiO}_{2}$ and $\mathrm{HfO}_{2}$ phases can occur in the $\mathrm{HfSiO}_{x}$ layer under annealing [25-28]. To deeply investigate this effect, the nature of phases formed, as well as the location of $\mathrm{Pr}^{3+}$ ions in the sample, we used APT to study the influence of annealing temperature on the structure.

The 3D isoconcentration surfaces representing the spatial distribution of $\mathrm{Si}$ (corresponding to $\mathrm{Si}^{+}, \mathrm{Si}^{2+}$, and $\mathrm{Si}^{3+}$ ions), $\mathrm{HfO}$ (corresponding to $\mathrm{HfO}^{2+}$ and $\mathrm{HfO}^{3+}$ ions), ${ }^{16} \mathrm{O}, \mathrm{O}_{2}^{+}$, and $\mathrm{Pr}$ (corresponding to $\mathrm{Pr}^{2+}$ and $\mathrm{Pr}^{3+}$ ions) elements in the Pr-doped $\mathrm{HfSiO}_{x}$ layer annealed at $1050{ }^{\circ} \mathrm{C}$ are shown in figures 4 (a) to (d). The isoconcentration maps of Si and HfO (figure 4(a)) highlight the phase separation between Si-rich and Hf-rich phases forming two interconnected phases upon the annealing treatment. The distribution of Si and $\mathrm{Pr}$ (figure 4(b)) reveals that Pr atoms are located outside of the Si-rich phase. Moreover, as we can observe by investigating the isoconcentration maps of the two oxygen peaks $\left(\mathrm{O}_{2}^{+}\right.$and $\left.{ }^{16} \mathrm{O}\right)$ in regards to the spatial location of the Si-rich and HfO-rich phases in figures 4(c) and (d), $\mathrm{O}_{2}^{+}$ions are mainly detected outside the Si-rich phase (figure 4(c)) whereas ${ }^{16} \mathrm{O}$ are identified outside the Hf-rich phase. These results allow us to conclude that oxygen atoms were evaporated in different ways from these two different phases. This highlights a difference in the environment of $\mathrm{O}$ atoms between the two phases present in the system as well as a difference in the evaporation field, with a lower evaporation field required to evaporate the Hf-rich phase. Otherwise, this result confirms that the nature of the ${ }^{16} \mathrm{O}$ peak can be different according to the phase. Figure 4(e) represents the isoconcentration maps performed on a slice in the previous $3 \mathrm{D}$ volume. It shows the distribution of $\mathrm{Si}, \mathrm{HfO}, \mathrm{Pr},{ }^{16} \mathrm{O}$, and $\mathrm{O}_{2}^{+}$in the Pr-doped $\mathrm{HfSiO}_{x}$ layer annealed at $1050{ }^{\circ} \mathrm{C}$. All these elements are nonhomogeneously distributed in the 


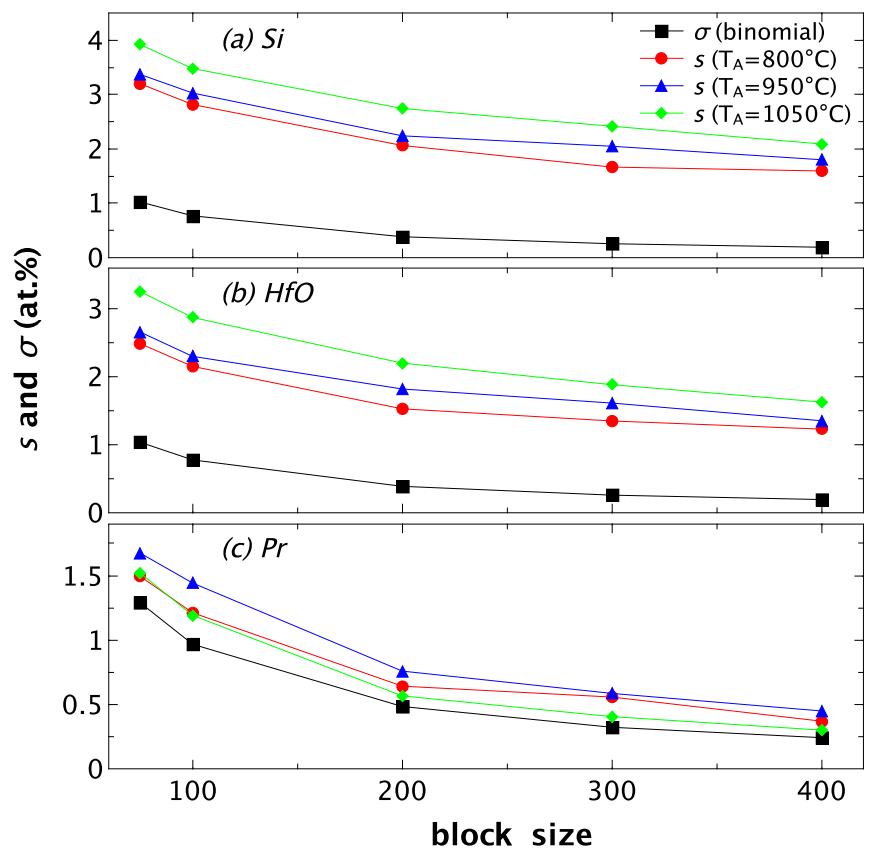

Figure 5. Statistical tests of randomness of (a) Si ions, (b) $\mathrm{HfO}$ ions, and (c) Pr ions distributions in Pr-doped $\mathrm{HfSiO}_{x}$ films annealed at $800{ }^{\circ} \mathrm{C}, 950{ }^{\circ} \mathrm{C}$, and $1050{ }^{\circ} \mathrm{C}$.

analyzed volume, as displayed in figures 4(a)-(d). As shown in figure 4(a), two regions can be clearly identified corresponding to Si-rich and Hf-rich phases, respectively named $\alpha$ and $\beta$ in figure 4(e). The presence of these two phases is governed by the $\mathrm{HfSiO}_{x}$ decomposition upon annealing, which should be finalized by the formation of $\mathrm{SiO}_{2}$ and $\mathrm{HfO}_{2}$ as proved by several studies [25-29]. Besides, it has been evidenced that the decomposition of the $\mathrm{HfSiO}_{x}$ layers occurs in the form of a spinodal decomposition [28, 30], which is consistent with the 3D isoconcentration surfaces observed in figure 4(a). Moreover, regarding the distribution of $\operatorname{Pr}$ elements in the volume (figure 4(e)), these atoms clearly appear to be located in Hf-rich phases. A similar behavior of RE dopant atoms has already been mentioned in the case of Er-doped $\mathrm{SiO}_{2}-\mathrm{HfO}_{2}$ [7], which explained that Er atoms can diffuse into $\mathrm{HfO}_{2}$ nanocrystals after heat treatment, leading to an improvement of the luminescence signal. The same maps were investigated on $\mathrm{Pr}$-doped $\mathrm{HfSiO}_{x}$ layers annealed at $800{ }^{\circ} \mathrm{C}$ and $950^{\circ} \mathrm{C}$ (not shown here), but these maps did not reveal a significant evolution of the phase decomposition or of a change in dopant location during the annealing process.

In order to confirm and quantify the nonhomogeneous distribution of atoms in the volume upon annealing, statistical tests of randomness described by Thuvander et al [31] were performed to observe the evolution of the atomic distribution upon sample annealing. Results of these tests for the distribution of $\mathrm{Si}, \mathrm{HfO}$, and Pr ions in the layers annealed at $800^{\circ} \mathrm{C}, 950^{\circ} \mathrm{C}$, and $1050^{\circ} \mathrm{C}$ are presented in figures 5 (a), (b), and (c), respectively. The goal of the statistical test of randomness is to compare the standard error $(s)$ of the frequency distribution of an element ( $\mathrm{Si}, \mathrm{HfO}$, and $\mathrm{Pr}$ ) extracted from APT reconstruction to the standard deviation $(\sigma)$ of the binomial distribution (case of randomness distribution). In the case of a homogeneous (random) distribution of elements in the material, both $s$ and $\sigma$ curves must be superimposed. All graphs represented in figure 5 show that $s$ and $\sigma$ curves are not superimposed, and confirm that these three elements, $\mathrm{Si}, \mathrm{HfO}$, and $\mathrm{Pr}$, are nonhomogeneously distributed in the analyzed volume; however, their evolution according to annealing seems to be different. In fact, for $\mathrm{Si}$ and $\mathrm{HfO}$ distributions, we can notice an up-shift of the $s$-curve while the temperature increases from $800^{\circ} \mathrm{C}$ to $1050{ }^{\circ} \mathrm{C}$ (figures 5(a), (b)). As a result, the distribution of ions is more homogeneous at the lower annealing temperature. This reveals an evolution of the matrix during the annealing treatment from $800{ }^{\circ} \mathrm{C}$ to $1050{ }^{\circ} \mathrm{C}$, which should correspond to a progressive phase separation between $\mathrm{SiO}_{2}$ and $\mathrm{HfO}_{2}$ phases observed in $\mathrm{HfSiO}_{x}$. In the case of $\mathrm{Pr}$ atoms (figure 5(c)), we can first observe an up-shift for the $s$-curve when the annealing temperature rises from $800{ }^{\circ} \mathrm{C}$ to $950{ }^{\circ} \mathrm{C}$, and then see a down-shift of the $s$-curve when the temperature increases from $950^{\circ} \mathrm{C}$ to $1050{ }^{\circ} \mathrm{C}$. The first step can be explained by considering the demixing of Si-rich and $\mathrm{HfO}$-rich zones and the formation of a Pr-rich area (located in Hf-rich phases, as evidenced previously in figure 4). The second stage can be ascribed to a redistribution of $\mathrm{Pr}$ atoms located in the Hf-rich phases. This result reveals a modification of $\operatorname{Pr}^{3+}$ ions' environment between the samples annealed at $950{ }^{\circ} \mathrm{C}$ and $1050{ }^{\circ} \mathrm{C}$, which could induce a change in the optical activities of these ions as was observed in the PL spectra shown in figure 2(a). Up to now, no Pr clusters have been evidenced in the matrix. Consequently, the change of $\operatorname{Pr}^{3+}$ ion 

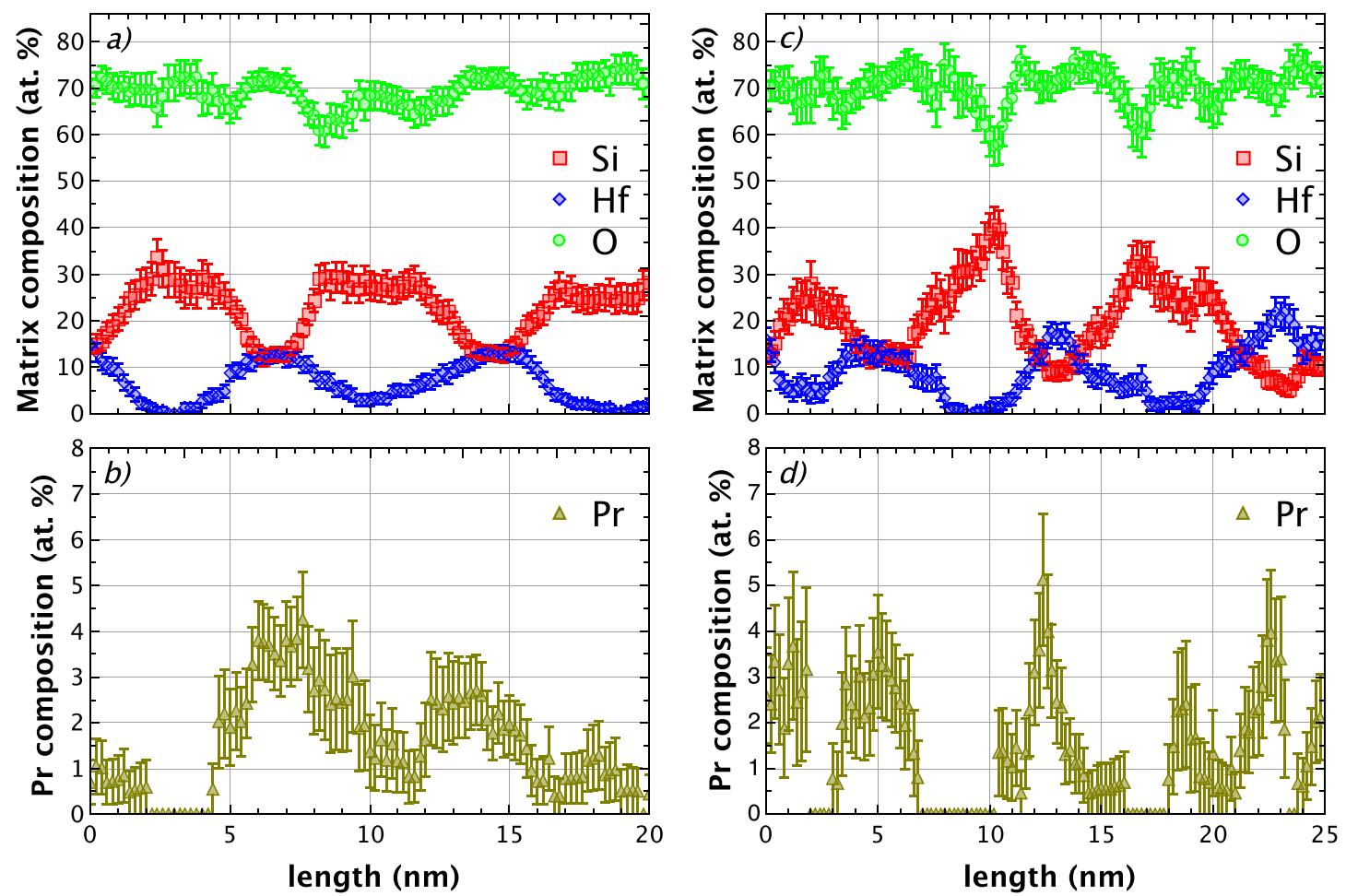

Figure 6. Composition profile computed on Pr-doped $\mathrm{HfSiO}_{x}$ annealed at (a), (b) $950{ }^{\circ} \mathrm{C}$, and (c), (d) $1050{ }^{\circ} \mathrm{C}$. (a), (c) Matrix composition ( $\mathrm{Si}, \mathrm{Hf}$, and O) and (b), (d) Pr composition. The sample volumes are, respectively, (a), (b) $2 \times 2 \times 20 \mathrm{~nm}^{3}$ and (c), (d) $2 \times 2 \times 25 \mathrm{~nm}^{3}$.

emission should be due to an evolution of the microstructure of the Hf-rich phase and the environment of $\operatorname{Pr}^{3+}$ ions.

In order to define the microstructure of these materials accurately, it can be helpful to focus on the composition of each phase. The composition profiles in the analyzed volumes were computed in the films annealed at $950^{\circ} \mathrm{C}$ and $1050^{\circ} \mathrm{C}$, and are presented in figures 6(a), (b), (c), and (d) respectively. As mentioned above, the composition of Si and $\mathrm{Hf}$ vary along the length according to the phase separation of Si-rich and HfOrich phases. The concentration of Pr atoms reaches a maximum of 4 at. $\%$ in the Hf-rich phase, and is almost zero in the Si-rich phase. Moreover, the distance between the cores of each type of phase (wavelength of the decomposition) varies from 8 to $10 \mathrm{~nm}$ for both samples. The mean chemical composition of Si-rich and Hfrich zones was determined by placing small boxes of $2 \times 2 \times 2 \mathrm{~nm}^{3}$ in the core of each zone in the entire volume. By counting the number of atoms of each species present in the boxes, a mean value of the composition of Si-rich and Hf-rich phases can be computed. The mean composition of Si-rich phase for the samples annealed at $950{ }^{\circ} \mathrm{C}$ and $1050{ }^{\circ} \mathrm{C}$ are, respectively, $X_{\mathrm{Si}}=31.3 \pm 3.2$ at. $\%$ and $X_{\mathrm{O}}=68.7 \pm 3.2$ at. $\%$, and $X_{\mathrm{Si}}=29.9 \pm 3.0$ at. $\%$ and $X_{\mathrm{O}}=70.1 \pm 3.0$ at.\%; this can be attributed unambiguously to the $\mathrm{SiO}_{2}$ phase. Regarding the Hf-rich phase, we can observe in figures 6(a) and (c) 7 to 11 at.\% of Si is counted in these zones. This suggests that the phase separation between $\mathrm{SiO}_{2}$ and $\mathrm{HfO}_{2}$ is still in progress. In fact, pseudo-binary phase diagrams of the $\mathrm{SiO}_{2}-\mathrm{HfO}_{2}$ system [32, 33] highlights the existence of a third compound, $\mathrm{HfSiO}_{4}$. Then, depending on the mole fraction of $\mathrm{SiO}_{2}$ and $\mathrm{HfO}_{2}$, the phase separation from $\mathrm{HfSiO}_{x}$ to $x \cdot \mathrm{SiO}_{2}+(1-x)$. $\mathrm{HfO}_{2}$ is realized, passing through an intermediate stage composed of $\mathrm{SiO}_{2}$ and $\mathrm{HfSiO}_{4}$ or $\mathrm{HfO}_{2}$ and $\mathrm{HfSiO}_{4}$. However, at this temperature $\left(\mathrm{T} \sim 1000{ }^{\circ} \mathrm{C}\right)$, the separation between the two phases should be in an advanced state. In this case, the presence of Si atoms is unexpected in the Hf-phase and could be considered as an artifact of the APT analysis. Since a difference in evaporation field exists between silica and hafnia, the composition measurements of a such complex nanometric structure (figure 4(a)) can be altered because of the well-known effect of local magnification [34] that can occur in bi-phased systems. Otherwise, this effect was previously evidenced in similar material $[24,25]$. The raw and corrected (from the local magnification effect) mean compositions of Hfrich phases was computed in the samples annealed at $950{ }^{\circ} \mathrm{C}$ and $1050{ }^{\circ} \mathrm{C}$. Results are reported in table 2 . There was no significant evolution of the composition of Hf-rich phases between these two samples. In each case, the nature of the Hf-rich phase could not directly be attributed to $\mathrm{HfSiO}_{4}$ nor $\mathrm{HfO}_{2}$. Finally, none of these results allowed us to extract with accuracy the stoichiometry of the Hf-rich phase from APT analysis, but they confirmed the favored location of Pr atoms in this Hf-rich phase. 
Table 2. Mean atomic concentration of Si, $\mathrm{O}, \mathrm{Hf}$, and $\mathrm{Pr}$ atoms in Hf-rich phases.

\begin{tabular}{lcccc}
\hline $\mathrm{HfSiO}_{x}: \mathrm{Pr}$ & $\mathrm{Si}($ at.\%) & $\mathrm{O}($ at.\%) & $\mathrm{Hf}($ at.\%) & $\operatorname{Pr}($ at.\%) \\
\hline $950{ }^{\circ} \mathrm{C}$ & $9.0 \pm 1.1$ & $71.5 \pm 1.7$ & $15.6 \pm 1.3$ & $3.9 \pm 0.7$ \\
$1050{ }^{\circ} \mathrm{C}$ & $7.9 \pm 1.1$ & $73.5 \pm 1.6$ & $16.1 \pm 1.4$ & $2.5 \pm 0.6$ \\
\hline \multicolumn{5}{c}{ Correction of local magnification effect } \\
\hline $950{ }^{\circ} \mathrm{C}$ & 0 & $73.2 \pm 1.9$ & $21.4 \pm 1.8$ & $5.4 \pm 1.0$ \\
$1050{ }^{\circ} \mathrm{C}$ & 0 & $75.7 \pm 1.8$ & $21.1 \pm 1.7$ & $3.2 \pm 0.7$ \\
\hline
\end{tabular}

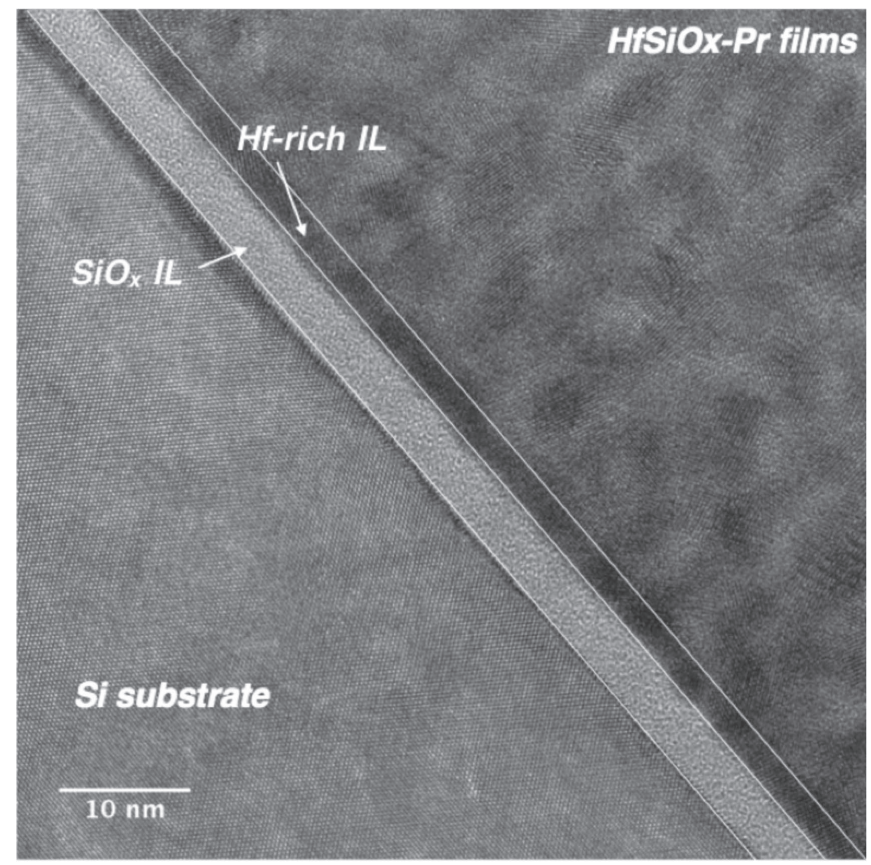

Figure 7. Cross sectional HRTEM micrograph of the $\mathrm{HfSiO}_{x}-\mathrm{Pr}$ sample annealed at $1050{ }^{\circ} \mathrm{C}$ oriented according the [011] zone axis of the $\mathrm{Si}$ substrate. $\mathrm{SiO}_{x} \mathrm{IL}$ denotes the thin $(\sim 4 \mathrm{~nm}) \mathrm{SiO}_{2}$ layer at the interface with the Si substrate. Hf-rich IL denotes the Hf-rich IL following the $\mathrm{SiO}_{x}$ IL.

\subsection{SAED and HRTEM results}

In order to elucidate the nature of the Hf-rich phase and to confirm the location of $\mathrm{Pr}^{3+}$ ions, we performed TEM analysis on the $\mathrm{HfSiO}_{x}-\mathrm{Pr}$ samples annealed at $950^{\circ} \mathrm{C}$ and $1050^{\circ} \mathrm{C}$. Figure 7 shows a cross sectional HRTEM image of the $\mathrm{HfSiO}_{x}-\mathrm{Pr}$ sample annealed at $1050^{\circ} \mathrm{C}$. The micrograph shows a nanocrystalline structure in this film and the formation of two interfacial layers (ILs). The observed dark and bright regions can be explained by the phase separation between Si-rich and Hf-rich phases already evidenced in the APT experiments (figure 4). The Hf-rich phase is clearly crystallized. These observations are consistent with previous investigations on phase separation of the $\mathrm{HfSiO}_{x}$ matrix, and were predicted by a phase diagram [24, 26, 32]. Based on the observed contrast, we can expect that the first IL (bright region, $\mathrm{SiO}_{x}-\mathrm{IL}$ ), with a thickness of $4 \mathrm{~nm}$, contains no or very little $\mathrm{Hf}$, and deals with $\mathrm{SiO}_{x}$ or $\mathrm{SiO}_{2}$. The second one seems more concentrated in $\mathrm{Hf}$ atoms (Hf-rich IL of about $\sim 3 \mathrm{~nm}$ ). Similar IL formation has already been evidenced and identified by TEM and APT experiments on $\mathrm{HfSiO}_{x}$ grown by magnetron sputtering [24]. The sample annealed at $950{ }^{\circ} \mathrm{C}$ presents a similar micrograph (not shown here).

The nature of the crystalline phase present in samples annealed at $950{ }^{\circ} \mathrm{C}$ and $1050{ }^{\circ} \mathrm{C}$ was examined from SAED patterns (figures 8 (a) and (b)). For both annealed samples, the four main diffraction rings of the SAED pattern can be indexed with the cubic fluorite type structure of $\mathrm{HfO}_{2}$ (space group $\mathrm{F} m \overline{3} m$ ). The $\mathrm{d}_{h k l}$ spacing extracted from these SAED are $2.89 \AA$, $2.51 \AA, 1.76 \AA$, and $1.49 \AA$ for the $950^{\circ} \mathrm{C}$ annealed sample, and $2.85 \AA$, $2.50 \AA, 1.75 \AA$, and $1.48 \AA$ for the $1050^{\circ} \mathrm{C}$ annealed sample. In both cases, the $\mathrm{d}_{h k l}$ spacings can be assigned to the (111), (200), (220), and (311) lattice planes of the cubic $\mathrm{HfO}_{2}$ phase (PDF 00-053-0550). No significant crystallographic phase transition is observed with the annealing treatment between $950{ }^{\circ} \mathrm{C}$ and $1050{ }^{\circ} \mathrm{C}$. This result is also demonstrated by previous $\mathrm{XRD}$ experiments where $\mathrm{HfO}_{2}$ phases were wrongly determined to be 

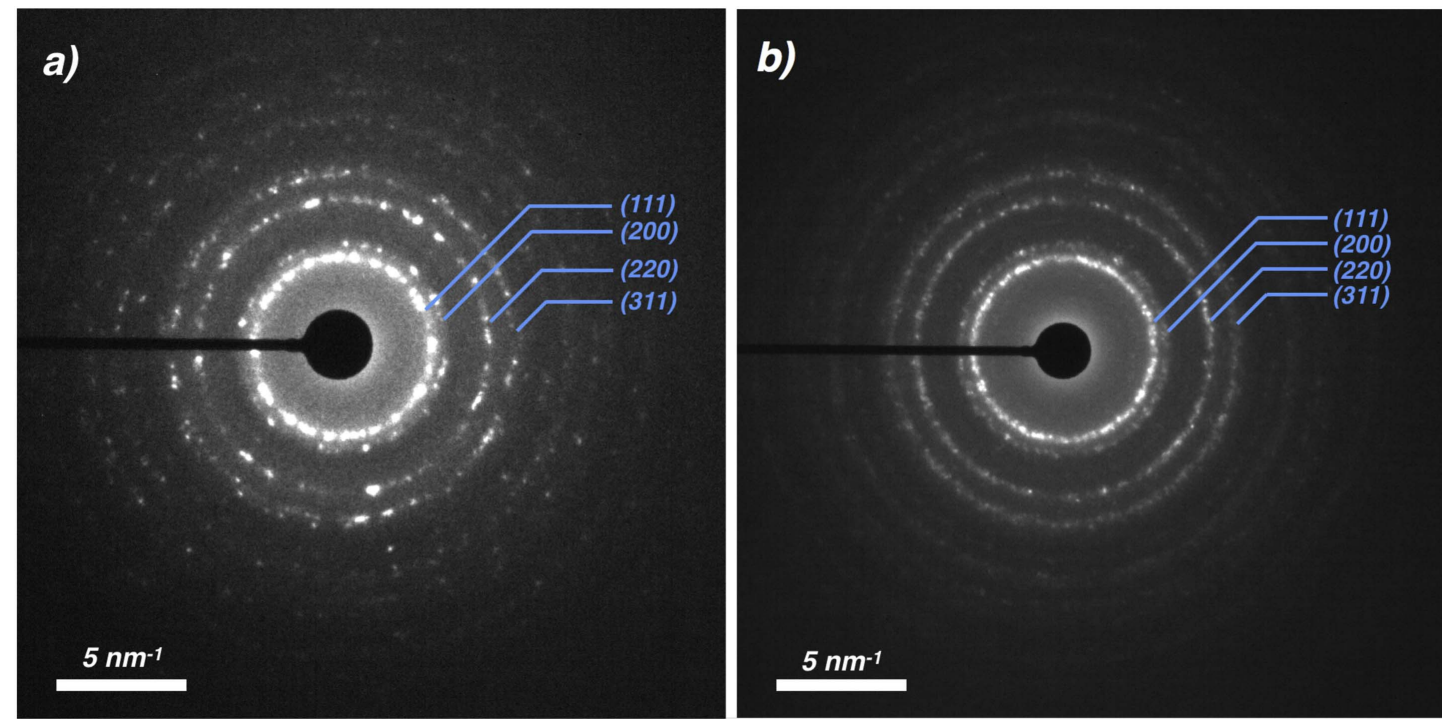

Figure 8. SAED pattern of $\mathrm{HfSiO}_{x}-\mathrm{Pr}$ samples annealed at (a) $950{ }^{\circ} \mathrm{C}$ and (b) $1050{ }^{\circ} \mathrm{C}$.

tetragonal [17]. It should be noted that an ambiguity can exist in indexing the $\mathrm{HfO}_{2} \mathrm{XRD}$ pattern where tetragonal and cubic phases can present a very similar pattern. As mentioned previously, RE-doped $\mathrm{HfO}_{2} \mathrm{can}$ present a cubic crystallographic phase. Based on the results described above, we can assume that this mechanism is similar in $\mathrm{Pr}$-doped $\mathrm{HfSiO}_{x}$ films where (i) spinodal decomposition leads to the formation of $\mathrm{HfO}_{2}$-rich and $\mathrm{SiO}_{2}$-rich nanocrystalline phases and (ii) $\mathrm{Pr}^{3+}$ ions stabilize the cubic phase of the $\mathrm{HfO}_{2}$ for an annealing temperature between $950^{\circ} \mathrm{C}$ and $1050^{\circ} \mathrm{C}$. Previous XRD and SAED experiments on the $1100{ }^{\circ} \mathrm{C}$ sample have shown that an increase in annealing temperature can induce a phase transformation to the monoclinic phase [17].

SAED and HRTEM experiments allow us to conclude that the Hf-rich phase identified with APT deals with $\mathrm{HfO}_{2}$ and that the Si atoms detected inside the Hf-rich phase (figure 6) are only due to the local magnification artifact occurring during APT experiments. It should be noted that the observed phases after decomposition $\left(\mathrm{SiO}_{2}\right.$ and $\left.\mathrm{HfO}_{2}\right)$ do not deal with those predicted by the $\mathrm{HfO}_{2}-\mathrm{SiO}_{2}$ phase diagram $\left(\mathrm{HfO}_{2}+\mathrm{HfSiO}_{4}\right.$ or $\mathrm{SiO}_{2}+\mathrm{HfSiO}_{4}$ ) or with the thermodynamic computation of a ternary Hf-Si-O diagram [32]. Moreover, no sign of the formation of $\operatorname{Pr}$ silicates (mainly $\mathrm{Pr}_{2} \mathrm{Si}_{2} \mathrm{O}_{7}$ ) has been observed.

\subsection{HAADF-STEM and EELS study}

The phase separation in Hf-rich and Si-rich interconnected structures occurring with annealing was confirmed by a combined HAADF-STEM and EELS experiments. The HAADF image, sensitive to the Z-contrast, of the $950{ }^{\circ} \mathrm{C}$ annealed sample is presented in figure 9(a). The micrograph exhibits high-Z (bright) and low-Z (dark) regions, which can be attributed to $\mathrm{HfO}_{2}$-rich (bright) and $\mathrm{SiO}_{2}$-rich (dark) phases. This result was confirmed by an EELS line scan profile performed over bright and dark areas from point A to point B (figure 9(a)). Figures 9(b) and (d) present the EELS line scan and extracted EELS spectra in the $\mathrm{SiO}_{2}$-rich and $\mathrm{HfO}_{2}$-rich phases in the O-K edge region. Both contrasted zones contain oxygen with a characteristic signal of an $\mathrm{O}-\mathrm{K}$ edge around $540 \mathrm{eV}$. Moreover, we note a low energy loss shift of the O-K edge in the bright region (for depths between 2-5 nm, 9-13 nm, and 17-22 nm (figure 9(d)), which confirms the chemical difference between dark and bright regions. Such a shift has already been evidenced between $\mathrm{SiO}_{2}$ and $\mathrm{HfO}_{2}$ phases $[24,35]$. The $\mathrm{Pr}-\mathrm{M}_{4,5}$ EELS spectrum is depicted in figure 9(c), and a typical EELS spectrum (extracted from $\mathrm{HfO}_{2}$-rich regions in figure 9(c)) is presented in figure 9(e). The Pr EELS signal, characterized by the typical two $\mathrm{M}_{5}$ and $\mathrm{M}_{4}$ white lines, is only present in the bright region (i.e. the $\mathrm{HfO}_{2}$-rich region). Moreover, the $\mathrm{M}_{5}$ and $\mathrm{M}_{4}$ peaks are located at $932 \mathrm{eV}$ and $951 \mathrm{eV}$, which is in agreement with the EELS signal of Pr ions [36]. The intensity ratio between $\mathrm{M}_{5}$ and $\mathrm{M}_{4}$ lines, which is directly related to the number of electrons in the $f$ shell, is measured to be $I_{M_{5}} / I_{M_{4}} \sim 1.4$. This ratio is a direct signature of the presence of $\operatorname{Pr}^{3+}$ ions as well as the damping of shoulders at the lower energy side of the $\mathrm{M}_{4}$ peak. In the case of Pr in the $4+$ valence state, the intensity ratio should be close to unity and damping of the shoulder should occur at the higher energy side of the $M_{5}$ peak [36-38]. This result allows us to conclude unambiguously that $\mathrm{Pr}$ ions are preferentially located in the $\mathrm{HfO}_{2}$-rich region, as already evidenced in the APT results and in the form of $\operatorname{Pr}^{3+}$. 

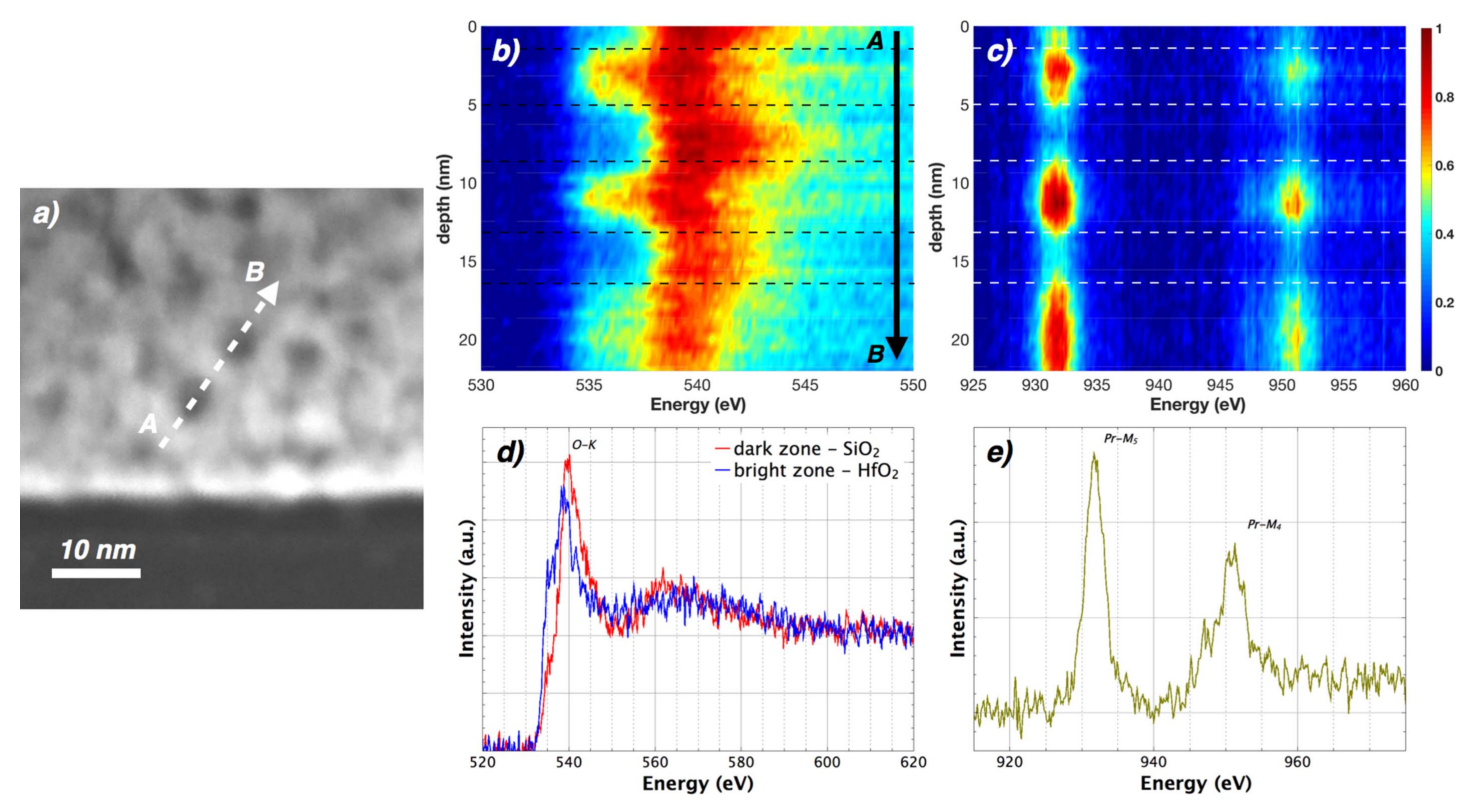

Figure 9. (a) HAADF-STEM image of cross-section lamellae on Pr-doped $\mathrm{HfSiO}_{x}$ films annealed at $950{ }^{\circ} \mathrm{C}$. EELS spectrum $2 \mathrm{D}$ image from a line scan (indicated by an arrow in (a)) of (b) the $\mathrm{O}-\mathrm{K}$ edge and (c) the $\mathrm{Pr}-\mathrm{M}_{4}$ and $\mathrm{Pr}-\mathrm{M}_{5}$ edges. EELS spectra extracted from Sirich and Hf-rich zones for (d) the O-K edge and (e) the $\mathrm{Pr}-\mathrm{M}_{4,5}$ edge.

\subsection{Discussion}

Numerous studies on undoped $\mathrm{HfSiO}_{x}$ systems have shown that the structural evolution of $\mathrm{HfSiO}_{x}$ thin layers under annealing is strongly dependent on the initial composition of the layer, but all of them agree that the phase decomposition occurring in these $\mathrm{HfSiO}_{x}$ layers should end on a bi-phased system composed of an amorphous $\mathrm{SiO}_{2}$ phase and crystalline $\mathrm{HfO}_{2}$ phase [24, 26-29]. Moreover, it has been shown by APT experiments that $\mathrm{Si}$ nanocrystals can grow in Si-rich $\mathrm{HfSiO}_{x}$ thin films [24, 25]. Here, the $\mathrm{Pr}^{3+}$ doping of the $\mathrm{HfSiO}_{x}$ thin layers does not seem to affect the phase separation mechanism compared to the undoped $\mathrm{HfSiO}_{x}$ system. APT analyses and TEM experiments have shown the phase separation, which began at $800^{\circ} \mathrm{C}$ (figure 5), between Si-rich and Hfrich phases; these results are attributed to $\mathrm{SiO}_{2}$-rich and $\mathrm{HfO}_{2}$-rich phases, respectively. Contrary to the $\mathrm{RE}^{3+}$ doping of $\mathrm{SiO}_{x}$ matrices for which a precipitation of RE ions in the form of clusters was evidenced in the case of $\mathrm{Er}^{3+}$ and $\mathrm{Ce}^{3+}$ doping by the formation of RE silicates [20,39], the presence of $\mathrm{Pr}^{3+}$ ions in the matrix does not lead to the formation of Pr oxides or Pr silicates during the annealing process at high temperature. We observed that $\mathrm{Pr}^{3+}$ ions tend to diffuse into the $\mathrm{HfO}_{2}$-rich phase from the beginning of the phase decomposition, and are already present in the $\mathrm{HfO}_{2}$-rich phase at $800{ }^{\circ} \mathrm{C}$. At higher annealing temperatures $\left(950{ }^{\circ} \mathrm{C}\right.$ and $\left.1050{ }^{\circ} \mathrm{C}\right)$, there is no significant evolution in the structure of the matrix in $3 \mathrm{D}$ mapping, and $\mathrm{Pr}^{3+}$ ions remain located in the $\mathrm{HfO}_{2}$-rich phase (figures 4 and 9). However, statistical testing (figure 5) revealed a more homogeneous distribution of $\mathrm{Pr}^{3+}$ in the host matrix after a $1050^{\circ} \mathrm{C}$ annealing treatment than after $950{ }^{\circ} \mathrm{C}$ annealing. This redistribution of $\mathrm{Pr}^{3+}$ in the $\mathrm{HfO}_{2}$-rich phase can be explained by a local modification of the $\mathrm{Pr}^{3+}$ environment provided by the crystallization of the $\mathrm{HfO}_{2}$-rich phase at high temperature. The presence of a crystalline form of $\mathrm{HfO}_{2}$ in $\mathrm{HfSiO}_{x}-\mathrm{Pr}$ thin layers has been evidenced via SAED patterns and TEM experiments (figures 7 and 8), and has been attributed to the cubic fluorite type structure of $\mathrm{HfO}_{2}$ of space group $\mathrm{F} m \overline{3} m$. This crystalline phase appeared only for annealing temperatures higher than $950{ }^{\circ} \mathrm{C}$. The thin film of $\mathrm{HfO}_{2}$ usually crystallizes in the monoclinic form, which is the most stable structure of the $\mathrm{HfO}_{2}$ crystallized state at low temperatures (around $\left.500{ }^{\circ} \mathrm{C}\right)[40,41]$. Several studies on RE-doped $\mathrm{HfO}_{2}$ have made similar observations by highlighting the stabilization of the cubic $\mathrm{HfO}_{2}$ phase $[10,11,15,42,43]$; this was observed here with SAED patterns (figure 8). The incorporation of RE dopants that have an ionic radius larger than that of $\mathrm{Hf}^{4+}$ cations tends to stabilize the cubic form of $\mathrm{HfO}_{2}$. According to the literature, the sevenfold coordination of $\mathrm{Hf}^{4+}$ cations is favored in the monoclinic structure [41]. However, the incorporation of $\mathrm{RE}^{3+}$ ions in the crystal lattice changes the coordination number of $\mathrm{Hf}^{4+}$ cations from sevenfold to eightfold, and leads to the stabilization of the cubic $\mathrm{HfO}_{2}$ form. Moreover, the $\mathrm{Hf}^{4+}$ cations can be substituted by $\mathrm{RE}^{3+}$ ions in the lattice; this substitution is followed by the formation of oxygen vacancies in order to maintain the electroneutrality of the crystal lattice and help stabilize the cubic crystalline phase [15]. The presence of these oxygen vacancies in the host matrix can introduce some defect states in the bandgap of $\mathrm{HfO}_{2}[44,45]$, which leads to the formation of recombination centers required for the excitation of electron-hole pairs. $\mathrm{Pr}^{3+}$ ions do not present an absorption band around $285 \mathrm{~nm}$, and consequently, the direct excitation of $\mathrm{Pr}^{3+}$ ions is not allowed with the $285 \mathrm{~nm}$ wavelength used to 
establish PL spectra (figure 2). This confirms the presence of an efficient energy transfer between $\mathrm{Pr}^{3+}$ ions and the host matrix. Considering that $\mathrm{Pr}^{3+}$ ions are mainly located in the cubic $\mathrm{HfO}_{2}$ phase, as proved by APT experiments (figure 4(e)) and confirmed by the EELS spectrum (figure 9(c)), and due to the overlapping of created defect states and absorption levels of $\mathrm{Pr}^{3+}$ ions, excitons can transfer their energy to $\mathrm{Pr}^{3+}$ ions and improve the PL emission. In this way, the enhancement of PL intensity observed from $\mathrm{T}_{A}=950^{\circ} \mathrm{C}$ to $\mathrm{T}_{A}=1000^{\circ} \mathrm{C}$, can be explained by the growth and stabilization of the cubic $\mathrm{HfO}_{2}$ phase providing more oxygen vacancies in that $\mathrm{HfO}_{2}$ crystalline phase. At a higher temperature some new diffraction peaks appear on XRD spectra [17], revealing the development of a monoclinic $\mathrm{HfO}_{2}$ phase. The cubic to monoclinic transformation could occur in an optically inactive configuration of $\mathrm{Pr}^{3+}$ ions, thus leading to the quenching of PL emission.

\section{Conclusion}

The structure of $\mathrm{HfSiO}_{x}-\mathrm{Pr}$ thin layers elaborated by magnetron sputtering was investigated by APT and TEM experiments. The phase separation between $\mathrm{SiO}_{2}$ and $\mathrm{HfO}_{2}$ has been highlighted for $\mathrm{T}_{A} \geqslant 800{ }^{\circ} \mathrm{C}$. The introduction of $\mathrm{Pr}^{3+}$ in $\mathrm{HfSiO}_{x}$ does not lead to the formation of Pr clusters in the host matrix even at high temperature. However, $\mathrm{Pr}^{3+}$ ions tend to diffuse in the $\mathrm{HfO}_{2}$ phase from the beginning of the phase separation. At high temperature, during the crystallization of the $\mathrm{HfO}_{2}$ phase, the substitution of $\mathrm{Hf}^{4+}$ by $\mathrm{Pr}^{3+}$ leads to stabilization of the cubic crystalline form of $\mathrm{HfO}_{2}$ and allows the formation of oxygen vacancies to ensure the electroneutrality of the crystal lattice. These oxygen vacancies, seen as defect states in the bandgap of $\mathrm{HfO}_{2}$, are efficient sensitizers for the excitation of $\mathrm{Pr}^{3+}$ ions, and permit the energy transfer between $\mathrm{Pr}^{3+}$ ions and the cubic $\mathrm{HfO}_{2}$ phase.

\section{Acknowledgments}

G Beainy acknowledges financial support from the Région Haute-Normandie.

\section{ORCID iDs}

Larysa Khomenkova (1) https://orcid.org/0000-0002-5267-5945

Etienne Talbot (1) https://orcid.org/0000-0001-6389-1670

\section{References}

[1] Choi J H, Mao Y and Chang J P 2011 Development of hafnium based high- $\kappa$ materials-a review Mater. Sci. Eng., R $7297-136$

[2] He G, Zhu L, Sun Z, Wan Q and Zhang L 2011 Integrations and challenges of novel high- $\kappa$ gate stacks in advanced CMOS technology Prog. Mater. Sci. 56 475-572

[3] Wilk G D, Wallace R M and Anthony J M 2001 High- $\kappa$ gate dielectrics: current status and materials properties considerations J. Appl. Phys. 895243

[4] Fujii M, Yoshida M, Kanzawa Y, Hayashi S and Yamamoto K $19971.54 \mu$ m photoluminescence of Er ${ }^{3+}$ doped into SiO $_{2}$ films containing Si nanocrystals: evidence for energy transfer from Si nanocrystals Appl. Phys. Lett. 71 1198-200

[5] Li J, Zalloum O H Y, Roschuk T, Heng C L, Wojcik J and Mascher P 2008 Light emission from rare-earth doped silicon nanostructures Adv. Opt. Technol. 2008295601

[6] Khomenkova L, An Y-T, Khomenkov D, Portier X, Labbé C and Gourbilleau F 2014 Spectroscopic and structural investigation of undoped and $\mathrm{Er}^{3+}$ doped hafnium silicate layers Phys. B 453 100-6

[7] Righini G C et al $2009 \mathrm{Er}^{3+}$-doped silica-hafnia films for optical waveguides and spherical resonators J. Non. Cryst. Solids $3551853-60$

[8] Minati L, Speranza G, Micheli V, Ferrari M and Jestin Y 2009 X-ray photoelectron spectroscopy of Er ${ }^{3+}$-activated SiO ${ }_{2}-\mathrm{HfO}_{2}$ glassceramic waveguides J. Phys. D: Appl. Phys. 4215408

[9] Jestin $\mathrm{Y}$ et al 2007 Erbium activated $\mathrm{HfO}_{2}$ based glass-ceramics waveguides for photonics J. Non. Cryst. Solids 353 494-7

[10] Gálvez-Barboza S, González L A, Puente-Urbina B A, Saucedo-Salazar E M and García-Cerda L A 2015 Preparation and characterization of Ce-doped $\mathrm{HfO}_{2}$ nanoparticles J. Alloys Compd. $643 \mathrm{~S} 62-6$

[11] Smirnova T P, Yakovkina L V and Borisov V O 2015 Impact of lanthanum on the modification of $\mathrm{HfO}_{2}$ films structure J. Rare Earths 33 857-62

[12] Wang J, Li H P and Stevens R 1992 Hafnia and hafnia-toughened ceramics J. Mater. Sci. 27 5397-430

[13] Tang J, Zhang F, Zoogman P, Fabbri J, Chan S-W, Zhu Y, Brus L E and Steigerwald M L 2005 Martensitic phase transformation of isolated $\mathrm{HfO}_{2}, \mathrm{ZrO}_{2}$, and $\mathrm{Hf}_{x} \mathrm{Zr}_{1-x} \mathrm{O}_{2}(0<\mathrm{x}<1)$ nanocrystals Adv. Funct. Mater. 15 1595-602

[14] Park M H, Schenk T, Fancher C M, Grimley E D, Zhou C, Richter C, LeBeau J M, Jones J L, Mikolajick T and Schroeder U 2017 A comprehensive study on the structural evolution of $\mathrm{HfO}_{2}$ thin films doped with various dopants J. Mater. Chem. C 5 4677-90

[15] Matović B, Bučevac D, Prekajski M, Maksimović V, Gautam D, Yoshida K and Yano T 2012 Synthesis and characterization of nanometric yttrium-doped hafnia solid solutions J. Eur. Ceram. Soc. 32 1971-6

[16] Yong-Qiang M, Zheng-Tang L, Li-Ping F and Shuai C 2014 Influence of rapid thermal annealing on the structure and electrical properties of Ce-doped $\mathrm{HfO}_{2}$ gate dielectric Chin. Phys. Lett. 3177702

[17] An Y T, Labbé C, Khomenkova L, Morales M, Portier X and Gourbilleau F 2013 Microstructure and optical properties of Pr ${ }^{3+}$-doped hafnium silicate films Nanoscale Res. Lett. 843 
[18] Khomenkova L, An Y-T, Labbé C, Portier X and Gourbilleau F 2012 Hafnia-based luminescent insulator for phosphor applications ECS Trans. 45 1119-128

[19] Thompson G B, Miller M K and Fraser H L 2004 Some aspects of atom probe specimen preparation and analysis of thin film materials Ultramicroscopy $10025-34$

[20] Talbot E, Lardé R, Pareige P, Khomenkova L, Hijazi K and Gourbilleau F 2013 Nanoscale evidence of erbium clustering in Er-doped silicon-rich silica Nanoscale Res. Lett. 839

[21] Debieu O, Bréard D, Podhorodecki A, Zatryb G, Misiewicz J, Labbé C, Cardin J and Gourbilleau F 2010 Effect of annealing and Nd concentration on the photoluminescence of $\mathrm{Nd}^{3+}$ ions coupled with silicon nanoparticles J. Appl. Phys. 108113114

[22] Roussel M, Talbot E, Pareige P and Gourbilleau F 2013 Influence of the supersaturation on Si diffusion and growth of Si nanoparticles in silicon-rich silica J. Appl. Phys. 113063519

[23] Bachhav M, Danoix F, Hannoyer B, Bassat J M and Danoix R 2013 Investigation of O-18 enriched hematite $\left(\alpha-\mathrm{Fe}_{2} \mathrm{O}_{3}\right)$ by laser assisted atom probe tomography Int. J. Mass Spectrom. 335 57-60

[24] Talbot E, Roussel M, Genevois C, Pareige P, Khomenkova L, Portier X and Gourbilleau F 2012 Atomic scale observation of phase separation and formation of silicon clusters in Hf higk- $\kappa$ silicates J. Appl. Phys. 11103519

[25] Talbot E, Roussel M, Khomenkova L, Gourbilleau F and Pareige P 2012 Atomic scale microstructures of high- $\kappa$ HfSiO thin films fabricated by magnetron sputtering Mater. Sci. Eng. B 177 717-20

[26] Khomenkova L, Dufour C, Coulon P-E, Bonafos C and Gourbilleau F 2010 High- $\kappa$ Hf-based layers grown by RF magnetron sputtering Nanotechnology 21095704

[27] Stemmer S, Li Y, Foran B, Lysaght P S, Streiffer S K, Fuoss P and Seifert S 2003 Grazing-incidence small angle x-ray scattering studies of phase separation in hafnium silicate films Appl. Phys. Lett. $833141-3$

[28] Kim H and Mcintyre P C 2002 Spinodal decomposition in amorphous metal-silicate thin films: phase diagram analysis and interface effects on kinetics J. Appl. Phys. 925094

[29] Lucovsky G, Rayner G B, Kang D, Hinkle C L and Hong J G 2004 A spectroscopic study distinguishing between chemical phase separation with different degrees of crystallinity in $\mathrm{Zr}(\mathrm{Hf})$ silicate alloys Surf. Sci. 566-568 772-6

[30] Lysaght P, Foran B, Stemmer S, Bersuker G, Bennett J, Tichy R, Larson L and Huff H R 2003 Thermal response of MOCVD hafnium silicate Microelectron. Eng. $69182-9$

[31] Thuvander M, Andrén H-O, Stiller K and Hu Q-H 1998 A statistical method to detect ordering and phase separation by APFIM Ultramicroscopy $73279-85$

[32] Shin D, Arróyave R and Liu Z-K 2006 Thermodynamic modeling of the Hf-Si-O system Calphad $30375-86$

[33] Maria J-P, Wickaksana D, Parrette J and Kingon A I 2002 Crystallization in $\mathrm{SiO}_{2}-$ metal oxide alloys J. Mater. Res. 17 1571-9

[34] Vurpillot F, Bostel A and Blavette D 2000 Trajectory overlaps and local magnification in three-dimensional atom probe Appl. Phys. Lett. 76 3127-9

[35] Agustin M P, Bersuker G, Foran B, Boatner L A and Stemmer S 2006 Scanning transmission electron microscopy investigations of interfacial layers in $\mathrm{HfO}_{2}$ gate stacks J. Appl. Phys. 100024103

[36] Lopez-Cartes C, Bernal S, Calvino J J, Cauqui M A, Blanco G, Perez-Omil J A, Pintado J M, Helveg S and Hansen P L 2003 In situ transmission electron microscopy investigation of Ce(iv) and $\mathrm{Pr}(\mathrm{iv})$ reducibility in a $\mathrm{Rh}(1 \%) / \mathrm{Ce}_{0.8} \operatorname{Pr}_{0.2} \mathrm{O}_{2-x}$ catalyst Chem. Commun. 0 644-5

[37] Manoubi T, Colliex C and Rez P 1990 Quantitative electron energy loss spectroscopy on M45 edges in rare earth oxides J. Electron Spectrosc. Relat. Phenom. 50 1-18

[38] Thole B T, van der Laan G, Fuggle J C, Sawatzky G A, Karnatak R C and Esteva J-M $19853 d$ x-ray-absorption lines and the $3 d^{9} 4 f^{n+1}$ multiplets of the lanthanides Phys. Rev. B 32 5107-18

[39] Beainy G, Weimmerskirch-Aubatin J, Stoffel M, Vergnat M, Rinnert H, Pareige P and Talbot E 2017 Correlation between the nanoscale structure and the optical properties of Ce-doped $\mathrm{SiO}_{1.5}$ thin films J. Lumin. 191 88-91

[40] Nishide T, Honda S, Matsuura M and Ide M 2000 Surface, structural and optical properties of sol-gel derived $\mathrm{HfO}_{2}$ films Thin Solid Films 371 61-5

[41] Štefanić G and Musić S 2001 Thermal behavior of the amorphous precursors of the $\mathrm{HfO}_{2}-\mathrm{Fe}_{2} \mathrm{O}_{3}$ system Thermochim. Acta 373 59-67

[42] Mendoza-Mendoza E, Quintero-García J S, Puente-Urbina B A, Rodríguez-Fernández O S and García-Cerda L A 2017 Synthesis and characterization of Ce-doped $\mathrm{HfO}_{2}$ nanoparticles in molten chlorides J. Alloys Compd. $692448-53$

[43] Chen S, Liu Z, Feng L, Che X and Zhao X 2014 Effect of ytterbium inclusion in hafnium oxide on the structural and electrical properties of the high- $\kappa$ gate dielectric J. Rare Earths $32580-4$

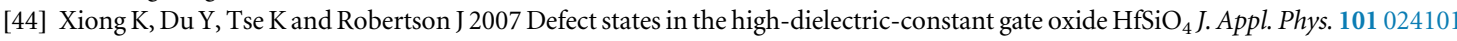

[45] Kumar S, Rai S B and Rath C 2018 Monoclinic to cubic phase transformation and photoluminescence properties in $\mathrm{Hf}_{1-x} \mathrm{Sm}_{x} \mathrm{O}_{2}$ $(x=0-0.12)$ nanoparticles J. Appl. Phys. 12355108 